\title{
A New Pedagogical Model for Teaching English for Specific Purposes: Collaborative Educational Project
}

\author{
Anastasia Ananyina $^{1 *}$, Irina Abramova ${ }^{1}$, Elena Shishmolina $^{1}$, and Anna Yessengaliyeva $^{2}$ \\ ${ }^{1}$ Petrozavodsk State University, Chair of Foreign Languages for Students of Humanities, 185910, \\ Petrozavodsk, Lenina, 33, Russia \\ ${ }^{2}$ L. N. Gumilyov Eurasian National University, Chair of Foreign Languages, 010008, Nur-Sultan, \\ Satpayeva, 2, Kazakhstan
}

\begin{abstract}
Raising young professionals is one of the main goals of ESP teachers across the globe, but in today's rapidly changing world it is complicated by the need to adapt learners to a demanding international working environment that puts heavy pressure on human resources. English communication skills are now sought by employers, so, English teachers worldwide need to help future graduates meet such high expectations. However, the practice has shown that options for improvement within national educational systems are limited. In artificially bilingual classrooms progress requires cooperation and networking of practitioners from different countries. This article presents the results of the first stage of an experimental collaborative educational project, which involved teachers and students from two state universities in Russia and Kazakhstan. It describes the beginning of implementing a relatively new pedagogical model for ESP teaching through designing a virtual crossborder learning environment simulating certain real-life professional communication situations. The aim of the paper is to analyze the initial impact of this model on developing certain soft skills and English communicative competence in the students of non-linguistic majors. The authors used the comparative analysis of data obtained through formal structured questionnaires. The statistical significance of the results was measured by the F-test and the paired Student's t-test The results suggest that extending ESP learning environment beyond borders helps ESP teachers to shift from purely academic settings to simulating real professional scenarios, thus developing students' English communicative competence, contributing to their professional socialization, and creating a sufficient level of stress to appeal to their motivation while avoiding discouragement.
\end{abstract}

\footnotetext{
* Corresponding author: ananyinastya@yahoo.com
} 


\section{Introduction}

Today's fast-changing world puts a lot of pressure on recent graduates, when they face a complicated and sometimes quite painful transition from learners to competent employees in their chosen field. Higher professional education is constantly adjusting to labor market demands, but in many cases it is still limited to teaching students packs of special professional skills, while in order to help students to become fully functioning professionals higher education institutions need to focus more on their professional socialization. Since building a professional identity involves developing not only necessary skills, values, norms, attitudes and behavior patterns, but also learning the language of the profession [1], the English language teachers share the burden of socializing the students of non-linguistic majors into their professional landscape. However, while postulating the prevalence of ESP (English for specific purposes) over general English courses, in practice the teachers often concentrate more on language itself rather than on socialization through language, which leads to too much English, and not enough specific purposes. So, eventually the graduates face the situation when they know a foreign language, but cannot use it in real life in order to promote their ideas, persuade people or solve professional conflicts.

A large number of studies and publications across the world stress the important role of higher education in developing students' English communicative competence [2-6]. However, many papers seem to omit the fact that due to the early start of English courses at school and the omnipresence of the English-language Internet content, university applicants often possess communicative competence or at least some of its components, including structural, discourse, strategic and even sociolinguistic competence. In Russia, this is also facilitated by the existence of the unified state examination on the English language (which is expected to become mandatory since 2022). So, the first question that arises in this context is why many university ESP learners who have already acquired the said competence still face so many difficulties with communicating properly in various social settings. This question is especially relevant for large post-soviet states, such as Russia and Kazakhstan, which constantly seek global integration. Unfortunately, this process is complicated by the low level of English skills among these countries' adult population. In the 2019 EF English Proficiency Index report, Russia and Kazakhstan were ranked number 48 and 93 out of 100 countries, which placed them into low proficiency and very low proficiency categories, respectively [7]. What's even more disturbing is that EF EPI rankings show no significant improvements for these two countries over the past nine years.

One of the possible answers to the above question can be the lack of focus on professional socialization, which helps students to master universal soft skills, and concentrating more on language socialization [8-11]. Another important thing is that even the existing studies on professional socialization through education emphasize many vital characteristics of this process - its dynamic and fluid nature [12], its continuity [13], its variability from person to person [14], significance of ethics, cultural awareness and personal commitment $[15,16]$ - but do not pay sufficient attention to socialization through healthy competition. Finally, the global practice of creating comprehensive teaching and learning environments for effective professional socialization of university students is quite limited. In order to complement the existing teaching practices, this paper offers a new ESP teaching model for non-linguistic university students with the special focus on their professional socialization, and presents the results of the first stage of an experimental collaborative educational project aimed at implementing this model. The study is aimed at investigating how this experimental pedagogical model impacts the development of universal soft skills and the students' subjective self-assessment of their progress 


\section{Materials and methods}

\subsection{Research hypothesis}

In accordance with the study aim the following hypothesis was formulated in order to be confirmed or rejected through the analysis of the survey data: creating a cross-border interuniversity ESP learning environment simulating real-life professional communication situations will help students to understand the importance of competitiveness and professional simulation for ESP learning, and will foster the development of certain soft skills and English communicative competence in general.

\subsection{Participants}

The first stage of this experimental study was performed at two partnering universities Petrozavodsk State University (PetrSU, Russia) and Gumilyov Eurasian National University (ENU, Kazakhstan). It involved 36 first-year students majoring in International Relations $(\mathrm{n}=36)$ aged from 17 to 19 years. Before the enrollment, they were classified into the intermediate category according to the results of the standardized EFL test (EF SET). In the context of this research, it was important to find two relatively homogenous and comparable groups of non-linguistic students studying English. So, the IR major was deemed optimal, because it allots more hours for ESP teaching and usually attracts more motivated learners, who understand the importance of the English language for their future profession.

\subsection{Methods and instruments}

The first stage of the experimental study described in this paper was organized in three successive parts: 1) a pre-survey, 2) a set of collaborative educational activities conducted at both universities, and 3) a post-survey. Some of the pre-survey and post-survey questions were identical in order to measure the impact of the experimental intervention on the participants. For assessing the results the authors used the comparative analysis of data obtained through formal structured pre- and post-questionnaires with closed-ended questions. The statistical significance of the results was measured by the F-test and the paired Student's t-test.

A pre-survey included two closed questions: "What kind of ESP learning environment do you prefer?" and "What kind of ESP learning environment do you find most effective and productive?" For both questions the respondents had the same set of answer options, from which they could chose as many answers as they wished: "Comfortable and predictable environment", "Competitive environment stimulating personal progress", and "Environment that simulates real-life professional communication".

After obtaining the initial answers, the study organizers immersed the participating students into a specifically designed learning environment, based on a system of joint educational activities implemented over a period of six months on a competitive basis. In other words, the participating students were involved into a number of interuniversity competitions, including linguistic, communicative, self-promoting, and artistic ones. In several cases (e.g., in the Digital Story Competition, Student Film Festival, and Drama Contest) the best performers were awarded on the basis of both expert and peer voting for additional objectivity, motivation, and peer-assessment skills development. Table 1 below summarized these activities, each of which was aimed at different aspects of students' professional socialization and different universal soft skills development: critical thinking, 
problem solving, communication, collaboration, creativity and ICT (information, communication and technology) literacy [17].

It should be noted that most of the planned activities (except for the purely artistic ones) were meant to have strong professional focus. For example, recordings and texts chosen for listening or translation informed students about various relevant professional, social or corporate responsibility issues. Digital products created by the students also had to be connected with their future profession (e.g., discuss professional ethical standards, present common professional communication situations, etc.). Another important thing is that all the activities were implemented via the Internet and other digital media, which was especially useful and relevant amid the current public health crisis. The table below lists only the activities implemented during the first stage of the experimental study, which is expected to take four years altogether. The next stages will see more complex and challenging collaborative interuniversity projects, such as professionally focused debates, discussions, interviews, round tables, presentations and research conferences, culminating in a large-scale online project (e.g., Model United Nations or Model Economic Forum) organized by the students.

Table 1. Interuniversity ESP learning activities aimed at students' professional socialization.

\begin{tabular}{|c|c|c|}
\hline Type of activity & Aspect of professional socialization & Soft skills \\
\hline $\begin{array}{l}\text { Individual language activities: } \\
\text { - Listening Comprehension } \\
\text { Competition } \\
\text { - Translation and Editing } \\
\text { Competition }\end{array}$ & $\begin{array}{l}\text { Increasing social and professional } \\
\text { awareness, learning about professional } \\
\text { ethics, building stress resilience }\end{array}$ & $\begin{array}{l}\text { Critical thinking, } \\
\text { problem solving, } \\
\text { creativity }\end{array}$ \\
\hline $\begin{array}{l}\text { Collaborative communication } \\
\text { activities: } \\
\text { - Face-to-face question-and- } \\
\text { answer sessions (individual } \\
\text { work) } \\
\text { - Group question-and-answer } \\
\text { sessions (team work) } \\
\end{array}$ & $\begin{array}{l}\text { Building contacts, learning how to create } \\
\text { a positive first impression, introducing } \\
\text { your region/country/town to future } \\
\text { partners, developing collaboration skills, } \\
\text { building stress resilience }\end{array}$ & $\begin{array}{l}\text { Critical thinking, } \\
\text { problem solving, } \\
\text { communication, } \\
\text { collaboration, } \\
\text { ICT literacy }\end{array}$ \\
\hline $\begin{array}{l}\text { Creative self-expression and } \\
\text { self-promotion activities: } \\
\text { - Digital Story Competition } \\
\text { "Choosing a Profession" } \\
\text { (individual projects) }\end{array}$ & $\begin{array}{l}\text { Learning and informing others about the } \\
\text { chosen professional field, developing } \\
\text { ability to stand out, developing ability to } \\
\text { find, plan and present arguments to } \\
\text { unfamiliar audience, learning how to } \\
\text { promote ideas and influence the opinions } \\
\text { of others } \\
\text { Developing project skills and ability to } \\
\text { work in a team, internalizing the } \\
\text { professional culture, practicing future } \\
\text { professional roles, building stress } \\
\text { resilience }\end{array}$ & $\begin{array}{l}\text { Critical thinking, } \\
\text { problem solving, } \\
\text { communication, } \\
\text { collaboration, } \\
\text { creativity, ICT } \\
\text { literacy }\end{array}$ \\
\hline $\begin{array}{c}\text { Artistic competitions: } \\
\text { - Poetry Reading Contest } \\
\text { (individual performances) } \\
\text { - Drama Contest (group } \\
\text { performances) } \\
\end{array}$ & $\begin{array}{l}\text { Developing creativity and "self-selling" } \\
\text { skills, building stress resilience } \\
\text { Developing project skills and ability to } \\
\text { work in a team, building stress resilience }\end{array}$ & $\begin{array}{c}\text { Problem solving, } \\
\text { communication, } \\
\text { collaboration, } \\
\text { creativity }\end{array}$ \\
\hline
\end{tabular}


After all the activities were completed, the post-survey was conducted, which included the same two closed questions as the pre-survey and an additional closed question: "Which professionally valuable skills did you develop while participating in the interuniversity English learning activities". The respondents were given four answer options: "Ability to think critically and independently", "Ability to set the goals and make plans for achieving them", "Ability to communicate in a team environment", and "Ability to work in a team, performing different social roles". The answer options were formulated in order to reflect the abovementioned core soft skills: critical thinking, problem solving, communication, collaboration, creativity, and ICT literacy. Since this paper presents only the results of the first stage of the experimental study, more core soft skills of the 21 st century, such as adaptability, innovation, initiative, cross-cultural skills, leadership and responsibility [17], will be investigated during the next stages of the study.

\section{Results}

\subsection{Students' assessment of ESP teaching and learning environment}

The most significant difference revealed after the comparative analysis of the pre-survey and the post-survey was between the number of the students from both study groups who appreciated competitive ESP learning environment as productive and motivating. In the PetrSU group this number increased almost twofold - from $33 \%$ to $62 \%$. A similar change was observed the ENU group - from $25 \%$ to $58 \%$. This shift was statistically significant in both groups, with $\mathrm{t}_{\text {obs }} 2.828>\mathrm{t}_{\text {crit }} 2.086$ for PetrSU and $\mathrm{t}_{\text {obs }} 2.345>\mathrm{t}_{\text {crit }} 2.201$ for ENU after paired Student's t-test analysis. In addition, the number of the ENU students who praised steady, comfortable and predictable ESP learning environment decreased from $59 \%$ to $42 \%$. The same indicator among the PetrSU students did not change, probably because the number of those who preferred such stress-free conditions initially was rather small (19\%). The results of the pre-survey and post-survey are shown in Figures 1 and 2. These data support the part of the hypothesis that states that cross-border ESP collaborations will convince students of the importance and usefulness of competitive learning activities, which eventually make them more accepting of competition as an integral part of their professional environment.

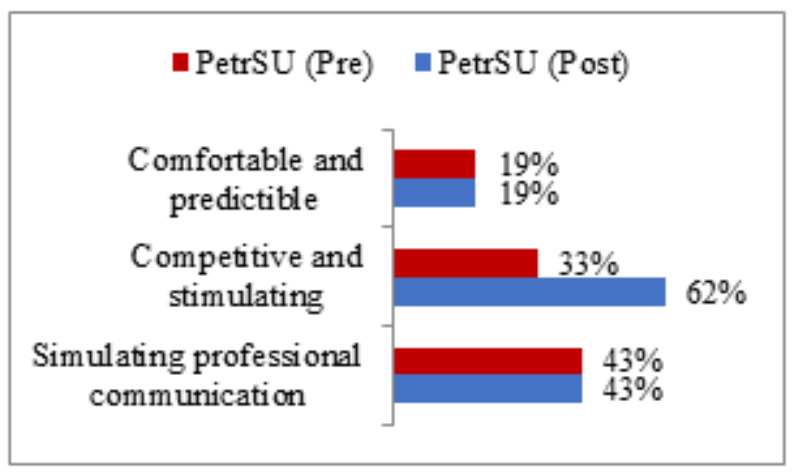

Fig. 1. Students' perceptions of the most productive ESP learning environments: pre- and post-survey results at PetrSU. 


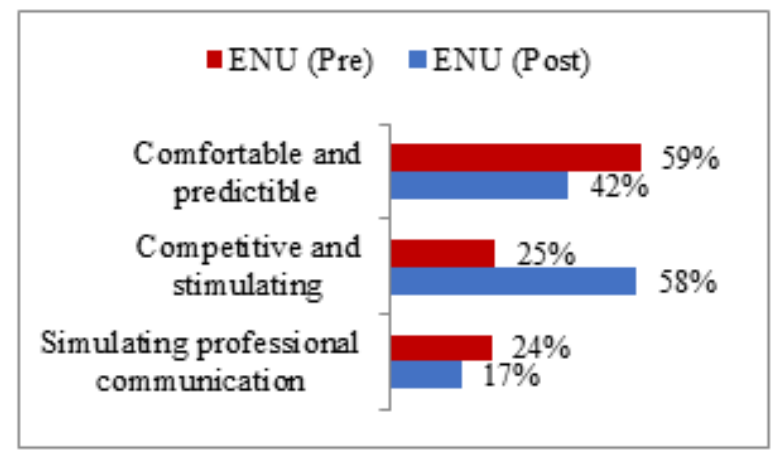

Fig. 2. Students' perceptions of the most productive ESP learning environments: pre- and post-survey results at ENU.

As the graphs show, the participants from Kazakhstan did not pick the ESP learning environment simulating real-life professional interaction as the most productive one. Only $24 \%$ of students chose this option during the pre-survery, and during the post-survey this number decreased by $7 \%$, which was not statistically significant. The attitude of PetrSU students towards this type of ESP learning environment did not change at all, although initially this indicator among Russian participants was quite high (43\%). Such results do not seem to be the problem at the first stage of the study involving the first-year students. Moving through the next stages of the experiment along with progressing through the course of study, the participants are expected to learn more about their future profession and to start correlating the offered collaborative ESP activities with the demands of the labor market.

\subsection{Students' self-assessment of their soft skills development}

After the first set of the experimental cross-border learning activities, students were asked to assess how these activities affected the level of the soft skills which they will most likely need for their future profession, including independent critical thinking, goal setting and planning, communication and teamwork/collaboration. The self-assessment results are presented in Figure 3.

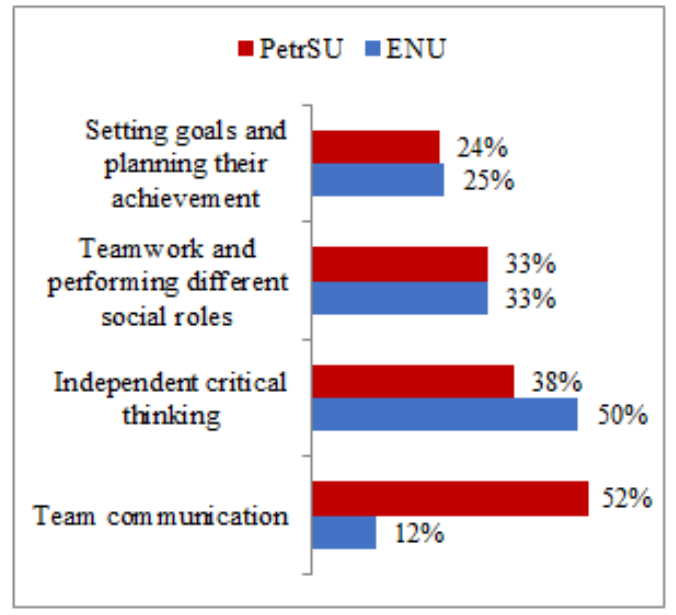

Fig. 3. Students' perceptions of soft skills development at PetrSU and ENU: post-survey results. 
The graph shows that the students from both PetrSU and ENU equally assessed the improvement of their goal-setting and planning skills (24\% and $25 \%$, respectively) and their ability to work in a team, performing different social roles (33\% in both groups). The largest improvement was seen by the respondents in their ability to think critically $-38 \%$ for PetrSU and $50 \%$ for ENU. This difference between the groups was not statistically significant, with the group arithmetic average $\mu_{\mathrm{PetrSU}}=6.9$ and $\mu_{\mathrm{ENU}}=7.08$. The largest discrepancy between the groups was observed with regard to the team communication skills: 52\% respondents from PetrSU saw the improvement of this category of skills, while in the ENU group this number was only $17 \%$. This difference was statistically significant $\left(\varphi{ }^{*}\right.$ obs $=2.86>\varphi^{*}$ crit $=1.64$ after F-test analysis $)$, and the reasons for it remain to be researched during the next stages of this experimental study.

\section{Discussion}

The described study was initiated with one important thing in mind: the gap between theory and practice in creating effective ESP teaching and learning environment outside nativespeaking countries. In recent years, many non-English-speaking countries have put in place various measures to increase the level of their populations' English skills. For example, the member states of the ASEAN Economic Community have been investing heavily in training English teachers and developing teaching and learning materials [18]. Chinese practitioners have been using small private online courses (SPOCs) and multimedia technology for college oral English teaching [19, 20]. Iranian, Indonesian and Turkish teachers benefit from mobile technologies and social networks, which help to intensify interaction to create real-like conditions for communication. [21-23]. However, this combination of real and virtual English language communication alone does not ensure productive collaboration and socialization. Some of the recent Russian and Kazakh publications discuss the effectiveness of interdisciplinary approach, early professional socialization, and using English as a medium of instruction for the formation of students' English communicative competence and professional values [24-28]. However, these papers deal with language or professional socialization of highly motivated students, and do not clearly show how to use the described methods and approaches for mass ESP teaching in mixed groups, which consist of students with different English proficiency levels. All in all, when implementing new approaches to creating effective ESP teaching and learning environment it is important to make sure that both students and teachers are not left struggling with language or cultural gaps. It is also necessary to remember that by simply translating national curricula into English we will not magically make them international [29], and that effective job-related socialization in English requires sustainable collaboration between universities and employers.

\section{Conclusion}

Systematic monitoring of the students' results during the first stage of this RussiaKazakhstan collaborative educational project suggests that focus on professional socialization during the ESP teaching process speeds up the development of universal soft skills, immerses the students into quasi-professional atmosphere, and creates solid foundation for building professional identity. Therefore, it can be concluded that professionally focused cross-border cooperation for ESP teaching and learning through the Internet and other digital media extends the limits of the classroom, shows students the importance of competitiveness as a stimulating factor, and creates the optimal level of 
stress to facilitate the development of universal soft skills and English communicative competence without discouraging students.

The authors of this study by no means claim that the presented pedagogical model for creating a competitive interuniversity ESP teaching and learning environment is a one-sizefits-all solution. In the future, it will require further monitoring, evaluation and improvement, as well as finding new unconventional methods for teaching new students of non-linguistic majors and raising next generations of professionals. Still, the current challenge for the ESP teachers is not only to teach students to communicate in English across cultures, but also to socialize them for future professional interaction. And although foreign-language professional socialization in an artificial learning environment has it limits, it is critically important for the non-native English language speakers. However, such socialization will need an increased arsenal of teaching methods and an expanded scope of teaching practices.

\section{Research disclaimer}

- Since all the obtained results are true only for the first-year students of International Relations, whether these or similar effects can be attributed to the students of other nonlinguistic university majors (including engineering, natural sciences, and technology) will require additional research.

- This paper presents the results of the first stage of the experimental collaborative educational project, and the results of all the further stages will be described, analyzed and interpreted in due time. The next stages will see more collaborative interuniversity projects, and will focus on additional soft skills.

-Although this paper focuses on students' professional socialization and the development of universal soft skills, linguistic data (including pronunciation fluency, vocabulary, grammar, speech rate, and utterance length) were also carefully considered, but were not included because of the length limitations.

The authors would like to express their sincere gratitude to all the study participants and all the university teachers and staff who contributed to the research delivery.

\section{References}

1. L.W. Perna, C. Hudgins. Association for the Study of Higher Education, 2-56 (1996)

2. D.P.T. Fatt. Higher Education, 22, 43-62 (1991)

3. F. Fang. Journal of Language Teaching and Research, 2, 111-116 (2010)

4. R.A. Fahrutdinova, R.R. Fahrutdinov, R.N. Yusupov. International Journal of Environmental \& Science Education, 11(6), 1285-1294 (2015)

5. K.M. Berkimbaev, G.A. Rizahodzhaeva. Herald of the L. N. Gumilyov Eurasian National University, 3(106), 99-104 (2015)

6. S. Kunanbayeva, Zh. Zhyltyrova. International Journal of Environmental \& Science Education, 11(14), 7262-7270 (2016)

7. EF English Proficiency Index (2019)

8. H.M. Cook, M. Burdelski, M. Encyclopedia of language and education (New York, Springer, 2008)

9. S.L. Thorne, R.W. Black, J.M. Sykes. The Modern Language Journal, 93, 802-821 (2009) 
10. S. Shiri. Foreign Language Annals, 48(1), 5-25 (2015)

11. X. L. Curdt-Christiansen. Language socialization: Encyclopedia of language and education (Netherlands, Springer, 2017)

12. J. Weidman, D. Twale, E. Stein. Ashe Eric Higher Education Report, 28(3), 1-118 (2001)

13. L. Wolf. A study of socialization of accelerated BSN graduates (Kent State University, Ohio, 2007)

14. A. Messersmith, A. Becoming a nurse: The role of communication in professional socialization (University of Kansas, Kansas, 2008)

15. H. C. R. de Swardt, G. H. van Rensburg, M.J. Oosthuizen. International Journal of Africa Nursing Sciences, 6, 1-7 (2017)

16. S. Melrose, C. Park, B. Perry. Creative Clinical Teaching in the Health Professions (PB Pressbooks, 2015)

17. Ch. Fadel. 21 st century skills: How can you prepare students for the new Global Economy? (2008)

18. V.-T. Nguyen, K.M. Ngoe. Professional development of English language teachers in Asia: Lessons from Japan and Vietnam (Routledge studies in world Englishes) (London, New York, Routledge, 2019)

19. R. Wu. Theory and Practice in Language Studies, 7(9), 756-763 (2017)

20. N. Guan, J. Song, D. Li. The application of multimedia technology in senior English teaching, in 2nd International Forum on Management, Education and Information Technology Application (IFMEITA 2017) (Atlantis Press, 2018)

21. I. Xodabande. Cogent Education, 4(1), 1347081 (2017)

22. K. Machmud, R. Abdulah. Journal of Arts and Humanities, 6(9), 01-11 (2017)

23. A. Taskiran, E.K. Gumusoglu, B. Aydin. Turkish Online Journal of Distance Education, 19(1), 100-116 (2018)

24. G. M. Kasimova. Bulletin of the Russian International Academy for Tourism, 4, 108$112(2013)$

25. M.N. Kicherova, G.Z. Efimova, T.V. Khvesko. Procedia-Social and Behavioral Sciences. 200, 442-448 (2015)

26. I.G. Kondrateva, M.V. Nazarova. Journal of Language and Literature, 6(3), 204-207 (2015)

27. L. Khalyapina, N. Popova, M. Kogan. Professionally-oriented content and language integrated learning (CLIL) course in higher education perspective, in ICERI 2017 Proceedings: 10th International Conference of Education, Research and Innovation, 1103-1112 (2017)

28. Z.Zh. Dosanova. Pedagogical Science and Practice, 2(20), 82-86 (2018)

29. K. Porntip, C. Chotima. Education in Thailand: An old elephant in search of a new mahout (Singapore, Springer, 2018). 